\title{
INDICADORES DE DESENVOLVIMENTO SOCIAL: IMPACTOS NA TAXA DE ANALFABETISMO NOS MUNICÍPIOS DO ESTADO DE SANTA CATARINA
}

\section{SOCIAL DEVELOPMENT INDICATORS: IMPACTS ON THE ILLITERACY RATE IN THE MUNICIPALITIES OF SANTA CATARINA}

\section{INDICADORES DE DESARROLLO SOCIAL: IMPACTOS SOBRE LA TASA DE ANALFABETISMO EN LOS MUNICIPIOS DEL ESTADO DE SANTA CATARINA}

\section{RESUMO}

0 objetivo deste estudo foi verificar o impacto dos indicadores de desenvolvimento social - índices de matrículas, de discentes e docentes e de gastos municipais com educação - na taxa de analfabetismo dos municípios do estado de Santa Catarina. Foram analisados 293 municípios. Com base em referencial teórico, foram elaboradas hipóteses de pesquisa com o propósito de validar 0 estudo. A pesquisa é de cunho descritivo e correlacional, e foi realizada por meio de análise documental, com abordagem quantitativa, e uso da técnica de Regressão Logística. Os resultados permitiram evidenciar que, no ensino pré-escolar, um número alto de alunos por professor prejudica a taxa de alfabetismo, e maior gasto no ensino infantil pode produzir melhores indicadores de analfabetismo. Infere-se que há confirmação da teoria de que os gastos públicos e a forma de gerenciamento influenciam os indicadores da qualidade do ensino, principalmente no ensino pré-escolar, o que pode revelar que, quanto mais cedo a criança entra na escola e quanto mais 0 município investe nela, melhor será o aproveitamento nos indicadores totais de analfabetismo da população.

PALAVRAS-CHAVE: Indicadores, impactos, desenvolvimento social, taxa de analfabetismo, Santa Catarina.

Sabrina do Nascimento - sabnascimento@gmail.com

Professora da Universidade do Oeste de Santa Catarina - Joaçaba - SC, Brasil

Débora Gomes Machado - debora_furg@yahoo.com.br

Professora da Universidade Federal do Rio Grande - Rio Grande - RS, Brasil

Jorge Eduardo Scarpin - jscarpin@gmail.com

Doutor em Controladoria e Contabilidade pela Universidade de São Paulo, Faculdade de Economia, Administração e Contabilidade São Paulo - SP, Brasil

Delci Grapégia Dal Vesco - Delcigrape@gmail.com

Professora da Universidade Estadual do Oeste do Paraná - Cascavel - PR, Brasil

Artigo submetido no dia 15.09.2015 e aprovado em 03.11.2016.

DOI: http://dx.doi.org/10.12660/cgpc.v21n70.56089 


\section{Abstract}

The study aims to verify the impact of social development indicators, enrollment rates, students, teachers, and municipal education spending on the illiteracy rate of the Santa Catarina municipalities, 293 municipalities were analyzed. From the theoretical framework, research hypotheses were drawn, to validate the study. The research was descriptive and correlational; it was made through a document analysis with a quantitative approach, using the logistic regression technique. The survey results highlight that pre-school education and a high number of students per teacher affect the literacy rate, and increased spending on kindergarten can produce better literacy indicators. It is inferred that this confirms the theory that public spending and the form of management influence on teaching-quality indicators, particularly in pre-school education, which may show that the sooner the child enters school and the more the municipality invests in these children, better will be total literacy indicators of the population.

Keywords: Indicators, impacts, social development, illiteracy rate, Santa Catarina.

\section{Resumen}

El estudio tuvo como objetivo verificar el impacto de los indicadores de desarrollo social, las tasas de matrícula, los estudiantes y profesores y el gasto municipal en educación en la tasa de analfabetismo de los municipios de Santa Catarina. Se analizaron 293 municipios. Desde el marco teórico se elaboraron hipótesis de investigación con el fin de validar el estudio. La investigación es de naturaleza descriptiva y correlacional, y se llevó a cabo por medio de un análisis de documentos con un enfoque cuantitativo, utilizando la técnica de regresión log ístiça. Los resultados del estudio han puesto de relieve que en la educación preescolar, un elevado número de alumnos por maestro afecta a la tasa de alfabettismo y una mayor inversión en el jardín de infantes puede producir mejores indicadores de analfabetismo. Infiere también, que existe una confirmación de la teoría de que el gasto público y la manera de gestión influencia en los indicadores de calidad educativa, especialmente en la enseñanza preescolar, que puede demostrar que, cuanto antes el niño entra a la escuela y cuanto más invierte el municipio en estos niños, mejor es el resultado en los indicadores de población total de analfabetismo.

Palabras clave: Indicadores, impactos, desarrollo docial, tasa de analfabetismo, Santa Catarina.

\section{INTRODUÇÃO}

estímulo para o crescimento econômico tem perpassado recomendações de políticas econômicas voltadas ao entendimento dos padrões de crescimento entre países e regiões, à alavancagem da taxa de crescimento, aos investimentos em capital humano e, mais especificamente, aos investimentos em educação, de forma a possibilitar um reflexo positivo no bem-estar da população.

Num país onde a riqueza está concentrada nas mãos de uma minoria - neste caso, o Brasil -, é natural que a maioria sofra com os problemas sociais. Slomski et al. (2004) defendem que o estado tem como obrigação manter o equilíbrio social e diminuir as desigualdades, no entanto ele tenta minimizar essa situação por intermédio de programas sociais. Os autores destacam que é de suma importância os programas sociais promoverem a inclusão social, contudo seus reflexos aparecerão apenas em médio e longo prazo com a potencialização do capital humano por meio da educação.

Estudos sobre os indicadores sociais têm permeado a academia. Varela e Martins (2005) analisaram os indicadores sociais gerados no setor público brasileiro e seu uso potencial no processo de planejamento e orçamento. Concluíram que é preciso aprofundar o conhecimento técnico quanto à utilização de indicadores sociais na definição de prioridades, alocação de recursos orçamentários, execução e avaliação de programas, buscando a identificação e a superação das principais dificuldades de operacionalização desses indicadores. 
O Índice de Desenvolvimento Humano (IDH) é um indicador de desenvolvimento social muito utilizado em pesquisas. Scarpin (2006) o conceitua como uma medida resumo do desenvolvimento humano que mensura a realização média de um país em três dimensões básicas: vida longa e saudável, conhecimento e nível de vida digno.

O estudo de Pereira (2009) investigou em que medida a qualidade da educação é um importante aspecto do desenvolvimento e está associada às outras dimensões da vida humana. Para verificar essas associações, a autora calculou a correlação entre a qualidade da educação dos municípios mineiros, mensurada pelo Índice de Desenvolvimento da Educação Básica (IDEB), e cada uma das demais dimensões do desenvolvimento humano, as quais foram medidas de acordo com o Índice Mineiro de Responsabilidade Social (IMRS). Pereira (2009) concluiu que o fato de a qualidade na educação estar associada às demais dimensões do desenvolvimento pode significar que esse aspecto, além de potencial causa da melhoria de outras dimensões do desenvolvimento, sofre um possível efeito de políticas voltadas para estas.

Diante do relevante contexto da educação para o desenvolvimento de uma nação, das políticas públicas de investimentos nessa área e dos indicadores sociais como medida de monitoramento e controle de crescimento, surge a seguinte questão desta pesquisa: No âmbito dos indicadores de desenvolvimento social, os índices de matrículas, de discentes e docentes e de gastos municipais com educação impactam na taxa de analfabetismo dos municípios do estado de Santa

\section{Catarina?}

Por esse motivo, o objetivo deste estudo é verificar o impacto dos indicadores de desenvolvimento social - os índices de matrículas, de discentes e docentes e de gastos municipais com educação - na taxa de analfabetismo dos municípios do estado de Santa Catarina. Os indicadores desenvolvidos como variáveis de estudo reportam-se aos índices de matrículas no ensino pré-escolar em relação aos residentes com idade entre 5 e 6 anos, bem como aos índices de discentes e docentes, sendo eles: discentes em relação ao número de docentes no ensino pré-escolar e escola pública, discentes quanto ao número de escolas de ensino fundamental e escolas públicas municipais, discentes em relação ao número de pré-escolas, discentes quanto ao número de pré-escolas e escolas públicas municipais. Os índices de gastos municipais com educação seriam o Ensino Fundamental per capita, a Educação Infantil per capita e a taxa de analfabetismo dos municípios do estado de Santa Catarina. Esses indicadores e suas respectivas variáveis são utilizados no modelo de regressão logística calculado, o qual tem o propósito de validar as hipóteses que respondem à indagação que permeia este estudo.

A relevância desta pesquisa repousa sobre os seguintes aspectos: a) a presença de externalidades que levam o governo à elaboração de políticas públicas de investimento em programas sociais para fomentar o desenvolvimento e o bem-estar da população; b) os bens públicos estão atrelados à correta alocação dos recursos que lhes são destinados; c) a educação é parte fundamental e necessita de investimento para sua ma- 
nutenção como bem público; d) as políticas públicas necessitam de monitoramento e avaliação por parte do ente público. Este estudo buscou contribuir para o fomento, a discussão e a ilustração do desempenho da educação no contexto dos índices estudados referentes aos municípios do estado de Santa Catarina.

Para Dal Vesco (2008), quando o cálculo privado diferir do cálculo social da produção ou do investimento, ocorrem as externalidades. Scarpin (2006) salienta que, na presença de externalidades, o interesse da sociedade inclui o bem-estar das demais pessoas afetadas. $O$ autor acrescenta que um dos mecanismos existentes para corrigir a alocação ineficiente de recursos em um mercado provocado por determinada externalidade são as políticas públicas. Na seção que segue, será apresentado o embasamento teórico dos temas contextualizados que dão suporte a este estudo.

\section{REVISÃO DE LITERATURA}

A revisão de literatura deste artigo compreende o entendimento sobre o analfabetismo e o analfabetismo funcional; sobre a educação como forma de desenvolvimento, que relaciona educação, trabalho, qualificação e renda; sobre a avaliação pelas entidades públicas, que discorre sobre a necessidade de controle e monitoramento de indicadores, sobretudo os sociais, e sobre os indicadores sociais, os quais os associam à distribuição de recursos públicos.

\section{Analfabetismo}

Conforme Vieira (2006), analfabeto é aquele que não aprendeu a ler e escrever; indica, conforme a origem da palavra, o desconhecimento das letras. De acordo com o INEP (2001, p. 19): "É considerada analfabeta a pessoa que declara não saber ler nem escrever um bilhete simples no idioma que conhece." Aquela que apenas assina o próprio nome também é considerada analfabeta.

Para Vieira (2006), a alfabetização é o passo inicial e fundamental para que jovens e adultos prossigam no processo de escolarização; ela contribui para a superação do sentimento de inferioridade dos adultos analfabetos, 0 que os leva a descortinar outros horizontes; além disso, contribui no combate à pobreza. Pinto et al. (2000) analisaram os principais fatores associados ao analfabetismo e identificaram que essa condição é um fenômeno que está presente, com maior predominância, não só nas regiões mais pobres do País como também na periferia dos grandes centros urbanos. Os autores constataram, ainda, que a frequência à escola não é um antídoto contra o analfabetismo, ressaltando a necessidade de as políticas de combate ao analfabetismo levarem em conta os diferentes perfis dos segmentos que estão nessa situação.

Lorenzo (2007) explica o analfabetismo funcional ao descrever quatro níveis de alfabetização: analfabetismo que corresponde à forma absoluta; alfabetismo rudimentar, em que o sujeito conhece as letras, lê palavras e pequenas frases isoladas, mas não compreende mensagens extraídas de textos; alfabetismo básico, em que o sujeito lê e compreende textos de média extensão e faz uso de informações extraídas destes, mas apresenta limitações quando os textos são mais extensos ou envolvem maior número de relações entre as informações presentes, e o alfabetismo pleno, no qual não há limita- 
ções para a compreensão ou busca de informações por meio da linguagem escrita dos textos cotidianos. Os analfabetos funcionais, conforme o autor, são os indivíduos que estão nos níveis de analfabetismo e alfabetismo rudimentar.

Educação como ferramenta de desenvolvimento

Para Scarpin (2006), a intervenção governamental pelas despesas públicas é dada por três vias. A primeira delas é o bem público propriamente dito que não pode ser feito pelo mercado, como é o caso da segurança pública. A segunda é considerada como bem de mérito, por exemplo, a educação, que é um bem julgado como especialmente desejável e oferecido pelo governo. Por fim, há a questão da assistência aos pobres. Embora o mercado seja eficiente na produção e distribuição dos bens desejados por indivíduos que têm dinheiro para gastar, não atende às necessidades dos que são pobres.

As relações entre educação e trabalho, entre qualificação e renda, são objetos de estudo de Psacharopoulos (1994), Flug, Spilimbergo, e Wachtenheim (1996) e Paiva (1998). Por meio deles, é possível depreender que houve mudanças na relação remuneração/ qualificação do indivíduo. Antes a população mais educada recebia salários e/ou benefícios mais elevados, e esse diferencial se justificava pelos anos de escolaridade e titulação obtida. Paiva (1998), em seu estudo, concluiu que o investimento em ensino fundamental é mais rentável que em outros níveis, o que pode acarretar significativas consequências, do ponto de vista da política educacional, as quais merecem ser debatidas.
As formas de medir esse diferencial individual estão no cerne da comprovação do "valor econômico da educação," mesmo quando os benefícios sociais de tais diferenças são considerados apenas de maneira difusa, imprecisa e residual (Scarpin, 2006). O autor (2006, p. 57) assevera que:

Na medida em que a sociedade do conhecimento se desenvolve, requerendo mais competência científica e técnica, o ensino superior também se expande, e, dentro dele, a educação profissional, necessária para o desempenho de tarefas especializadas que são típicas da atividade industrial, assim como das atividades mais complexas no setor da indústria e dos serviços.

Ferranti et al. (2002) salientam que, por meio de um documento do Banco Mundial sobre a América Latina, a demanda por maiores competências está aumentando mais do que a por trabalhadores menos qualificados na maior parte dessa região. Resta, então, o seguinte desafio: a desigualdade de salários tende a aumentar enquanto as desigualdades de acesso à educação permanecerem, e a falta de competências pode se tornar uma restrição para o desenvolvimento econômico. Os autores explicam que, em contrapartida, é também uma oportunidade, pois a demanda potencial crescente por educação abre a oportunidade de acelerar o crescimento da produtividade da economia por meio da redução da distância entre educação e tecnologia. "Para conseguir isto, as políticas devem responder de forma rápida, de tal maneira que a demanda por mais e melhor educação se traduza de fato em níveis educacionais maiores e melhores para 
a força de trabalho, e maior produtividade no nível das firmas" (Ferranti et al., 2002, p. 5).

Pimentel e Haddad (2005) complementam que se pode considerar a educação de duas formas. Primeiro, do ponto de vista regional: trata-se de um insumo em sua função de produção, cujo impacto é elevar a produtividade do trabalho, aumentando o bem-estar regional como um todo. Segundo, da perspectiva do indivíduo: a educação, ao elevar sua produtividade marginal, aumenta sua remuneração, o que lhe permite uma elevação do bem-estar e, mais do que isso, pode funcionar como uma espécie de impulso para superar a pobreza.

O estudo de Marquetti, Berni, e Hickmann (2005) revelou que, no Estado do Rio Grande do Sul, a acumulação de capital humano na forma de ensino fundamental apresenta efeito positivo sobre o crescimento econômico, sendo que isso não é verdadeiro para a acumulação de capital humano na forma de ensino médio e superior.

\section{Avaliação pelas entidades públicas}

De acordo com Scarpin (2006), a discussão sobre o papel da intervenção governamental na economia, para fins de alocação equitativa dos recursos da sociedade, tem como embasamento a teoria dos bens públicos para a justificativa da alocação dos recursos nacionais entre o setor público e privado, cuja finalidade é fornecer parte dos bens requeridos pela população. Essa teoria, segundo o autor, visa analisar a eficiência do uso de recursos pelo setor público.

Para Meirelles (1966), citado por Slomski (2001), a administração pública representa o aparelhamento do Estado preordenado à realização de seus serviços, visando à satisfação das necessidades coletivas. E, para que o Estado atinja seus propósitos, é preciso organizar-se. Nas entidades públicas, essa organização cabe, em parte, à controladoria.

Slomski (2001) salienta que, na estrutura administrativa dos municípios, a controladoria deveria ter a condição de Secretaria Municipal, para, em conjunto com o gestor máximo - no caso, o prefeito -, definir as necessidades informativas para a tomada de decisão em todos os níveis, produzindo, assim, interface nas atividades e, por consequência, melhor gerenciamento das informações.

Para essa organização, surgem necessidades informativas que perpassam pelo controle administrativo, o qual, por sua vez, requer acompanhamento que pode ser realizado por meio da avaliação e do monitoramento dos indicadores de desempenho sociais. De acordo com Varela e Martins (2005), a avaliação de programas e projetos sociais é um tema presente na sociedade e, no contexto das entidades públicas, deve ser entendida como exercício permanente de comparação entre o planejado e o executado, com a finalidade de contribuir para a tomada de decisão em relação aos programas e melhorarias necessárias aos futuros planejamentos.

Slomski et al. (2004) explicam que cada vez mais são realizados diagnósticos para determinar a eficiência das políticas sociais quanto à utilização de seus recursos. Sendo assim, é indispensável a análise objetiva de cada situação social a ser modificada. Entretanto, os autores defendem que, com isso, não bastam as descrições quantitativas das 
carências da população; é necessário apresentar, também, outras informações que permitam interpretá-las.

Varela e Martins (2005) salientam que o uso de indicadores no processo orçamentário ganha destaque quando a ênfase deixa de ser a função controle e passa a ser a gerência e, logo em seguida, o planejamento das ações governamentais. Assim, a necessidade de informação sobre "em que" e "para que" se gastam os recursos públicos é adicionada àquela sobre "o que" o governo adquire, tornando proeminente o processo de mensuração das ações orçamentárias.

O orçamento de desempenho, segundo Varela e Martins (2005), dá ênfase à gerência e à administração e, consequentemente, aos custos e às realizações das atividades, ou seja, à implementação dos programas governamentais. Portanto, os tipos de indicador a serem usados seriam os de insumo, processo, output, eficiência e eficácia. Os autores explicam que, em relação à medida que proporciona a avaliação, foi estabelecido que cada programa deve conter indicadores que quantifiquem a situação que 0 programa tem por fim modificar, bem como os valores e metas das atividades e os projetos componentes do programa.

No tocante às políticas de investimento voltadas à educação no Brasil, em 2006, houve a regulamentação do Fundo de Manutenção e Desenvolvimento da Educação Básica e de Valorização do Magistério (Fundeb). Para Campos e Cruz (2009), a regulamentação desse órgão representou um avanço no financiamento da educação pública brasileira, pois vinculou uma parcela considerável de receitas à manutenção de todas as mo- dalidades do ensino básico. Com sua universalização, esse fundo pode contribuir para a redução do analfabetismo, entre outros benefícios. Entretanto, os autores destacam que a política de vinculação dos recursos, isoladamente, pode não ser suficiente para a mitigação de todos os problemas apresentados pela educação pública brasileira.

Conforme Fernandes et al. (2008), além do Fundeb, teve-se o Fundo de Manutenção e Desenvolvimento do Ensino Fundamental e de Valorização do Magistério (Fundef). Posteriormente, foi criado o Sistema de Avaliação da Educação Básica (Saeb) e os Parâmetros Curriculares Nacionais (PCNs), que são políticas educacionais que, ao mesmo tempo, oferecem autonomia, ditam parâmetros que são cobrados por meio de avaliação, entre outros programas e suas formas específicas de avaliação.

\section{Indicadores sociais}

Para Pereira (2009), o uso de indicadores tem se mostrado fundamental para otimizar a distribuição dos recursos disponíveis, buscando melhor resultado das políticas implementadas, especialmente em ambientes onde esses recursos são escassos e a demanda por serviços é crescente. Dessa forma, a mensuração do desenvolvimento ganha destaque na agenda dos governos locais, os quais pretendem implementar políticas de desenvolvimento socioeconômico.

A autora salienta que, embora haja grande utilidade dos indicadores, é essencial salientar que sua interpretação deve ser acompanhada de uma análise detalhada do fenômeno estudado, uma vez que o alcance dos indicadores é limitado como tentativa 
de captar num simples número a complexa realidade social. Pereira (2009) destaca que existem várias tipologias de classificação de indicadores sociais, dependendo, em especial, do fim a que se destinam, da etapa do ciclo de formulação e avaliação de políticas públicas, do seu grau de complexidade e da época em que foram criados.

Para Varela, Martins, e Corrar (2006), uma das iniciativas mais conhecidas quanto ao uso de indicadores sociais é a da Organização das Nações Unidas (ONU), que, na década de 1990, criou o IDH, apresentando uma inovação ao introduzir, em sua concepção, as variáveis longevidade e educação, além da renda, para comparar o grau de desenvolvimento dos países. Vale destacar, segundo Pereira (2009), que o conceito de desenvolvimento humano como expansão das capacidades também inclui o papel da ação humana como agente ativo de mudanças e não apenas considera o homem como beneficiário passivo do progresso social e econômico.

Outras experiências surgiram com base no $\mathrm{IDH}$, sendo o caso do Índice Paulista de Responsabilidade Social (IPRS) construído pela Fundação Sistema Estadual de Análise de Dados (Seade), órgão do governo do estado de São Paulo, com o objetivo de classificar os municípios paulistas segundo a qualidade de vida dos habitantes.

Varela, Martins, e Corrar (2006) salientam que uma das principais preocupações relacionadas à gestão pública é como alocar os escassos recursos públicos na prestação de serviços de maneira eficaz e efetiva. Dessa forma, o interesse não se restringe apenas às modificações nas condições de riqueza, longevidade e escolaridade da população, mas também aos recursos utilizados para alcançar essas mudanças.

\section{PROCEDIMENTOS METODOLÓGICOS}

Este trabalho se constitui em uma investigação de natureza descritiva e correlacional. Cooper e Schindler (2003, p. 136) ensinam que o estudo descritivo "se refere a uma questão ou hipótese na qual o pesquisador pergunta ou declara algo a respeito de tamanho, forma, distribuição ou existência de uma variável." Para Sampieri, Collado, e Lucio (2006, p.104), pesquisas de natureza correlacional "têm como objetivo avaliar a relação entre duas ou mais variáveis ou conceitos". Nesse contexto, o propósito desta pesquisa foi verificar o impacto dos indicadores de desenvolvimento social - os índices de matrículas, de discentes e docentes e de gastos municipais com educação - na taxa de analfabetismo dos municípios do estado de Santa Catarina.

A população deste estudo é composta pelos 293 municípios do estado de Santa Catarina, conforme o censo do IBGE de 2000. $\mathrm{Na}$ amostra, foram utilizados todos os municípios, configurando-se como uma amostra censitária. Cabe mencionar que o estudo apresenta uma questão de pesquisa que o orienta e que, para prover respostas a essa indagação, apresentam-se, na pesquisa, três hipóteses centrais, a saber:

$\mathrm{H} 1$ - Os Indicadores de percentuais de matrículas de discentes no ensino infantil e fundamental não trazem impacto na taxa de analfabetismo dos municípios de Santa Catarina.

H2 - Os Indicadores de discentes e docen- 
tes não trazem impacto na taxa de analfabetismo dos municípios de Santa Catarina. H3 - Os Indicadores de gastos municipais com educação não trazem impacto na taxa de analfabetismo dos municípios de Santa Catarina.

As hipóteses estão consubstanciadas nos estudos de Ferranti et al. (2002), Marquetti, Berni, e Hickmann (2005), Fernandes et al. (2008), Campos e Cruz (2009), os quais utilizaram variáveis semelhantes.

Quanto à abordagem do problema, a pesquisa é de natureza quantitativa quando faz uso da análise multivariada dos dados por meio da técnica de Regressão Logística para respondê-la. Por essa abordagem, Oliveira (2001) afirma que é possível quantificar opiniões e dados para o emprego de recursos e técnicas estatísticas. Boudon (1989, p. 24) destaca que "as pesquisas quantitativas podem ser definidas como as que permitem recolher, num conjunto de elementos, informações comparáveis entre um elemento e outro". A técnica de Regressão Logística foi

Tabela 1. Codificação da variável classificatória selecionada por seu potencial de correlacionar dois grupos de variáveis classificatórias. De acordo com Hair Júnior et al. (2005, p. 10), essa técnica é conceituada como "uma forma especializada de regressão que é formulada para prever e explicar uma variável categórica binária (dois grupos), e não uma medida dependente métrica". Maroco (2007, p. 684) destaca que essa ferramenta "é uma técnica de regressão a utilizar para modelar a ocorrência, em termos probabilísticos, de uma das duas realizações das classes da variável (...) o modelo logístico permite avaliar também a significância de cada uma das variáveis independentes no modelo". Como o modelo de regressão logística trabalha apenas com variáveis binárias, optou-se por categorizar a variável de analfabetismo. Assim, municípios com baixo analfabetismo, inferior a $10 \%$, foram categorizadas com valores iguais a zero e municípios com alto analfabetismo, superior a $10 \%$, foram categorizados com valores iguais a um, para que 0 modelo pudesse ser operacionalizado. A seguir, apresenta-se a Tabela 1, com as variáveis classificatórias utilizadas na Regressão Logística.

\begin{tabular}{l|c|c}
\hline Valor original & Valor interno & Número de municípios \\
\hline Municípios com analfabetismo $<10 \%$ & 0 & 108 \\
\hline Municípios com analfabetismo $>10 \%$ & 1 & 185 \\
\hline
\end{tabular}

Fonte: Dados da pesquisa.

O estudo deu-se por meio de uma pesquisa documental. Para Lüdke e André (1986, p. 38), "a análise documental pode se constituir numa técnica valiosa de abordagem de dados qualitativos, seja complementando as informações obtidas por outras técnicas, seja desvendando aspectos novos de um tema ou problema". Destaca-se, ainda, que os dados obtidos são de natureza primária.
De acordo com Lakatos e Marconi (1999, p. 159), esses dados são "[...] históricos, bibliográficos e estatísticos; informações, pesquisas e material cartográfico, arquivos oficiais e particulares; registros em geral; documentação pessoal etc." Sendo assim, a seguir, serão apresentadas as etapas correspondentes à fase de coleta dos dados para a consecução deste estudo. 
A coleta dos dados foi dividida em três etapas. A primeira aconteceu em 23 de outubro de 2009, por meio da coleta no site do Instituto Brasileiro de Geografia e Estatística - IBGE (www.ibge.gov.br), das informações relacionadas à população dos 293 municípios analisados, dos índices de Ensino - Matrículas, Docentes e Rede Escolar em 2008 e a População e Domicílios. Para tanto, cabe mencionar que se realizou a exclusão das informações relacionadas aos índices que correspondem ao Ensino Superior, à Educação acima de 30 anos e às diferenciações por gênero no item "residente." Na segunda etapa, realizou-se a coleta das informações no site do Tesouro Nacional (www.tesouro.fazenda.gov.br), em 24 de outubro de 2009, as quais são pertinentes as despesas municipais com Educação e suas derivações nos demonstrativos públicos de cada município investigado no período de 2005 a 2008. Nesse contexto, inicia-se a terceira etapa que compreende a coleta das informações do Índice de Desenvolvimento Humano Mundial (IDH-M), disponível por meio do software Atlas do Desenvolvimento Humano do Brasil - versão 1.0.0. De posse dos dados, realizou-se a criação de um banco de dados confeccionado a partir de uma planilha eletrônica no Microsoft Excel, que foi utilizado na importação das informações para o software SPSS, as quais foram analisadas com auxílio da regressão logística. A Figura 1 apresenta todas as fases perpassadas por esta pesquisa, o que proporciona um bom entendimento sobre ela. Aborda a questão de pesquisa, o objetivo geral e a amostra censitária dos 293 municípios do estado de Santa Catarina na primeira fase. Demonstra todos os locais onde foram coletadas as informações e a geração do banco de dados com as 18 variáveis analisadas pela Regressão Logística na segunda fase. Por fim, na terceira fase, apresenta a análise dos dados das 18 variáveis, a fim de validar o modelo e as três hipóteses deste estudo. 


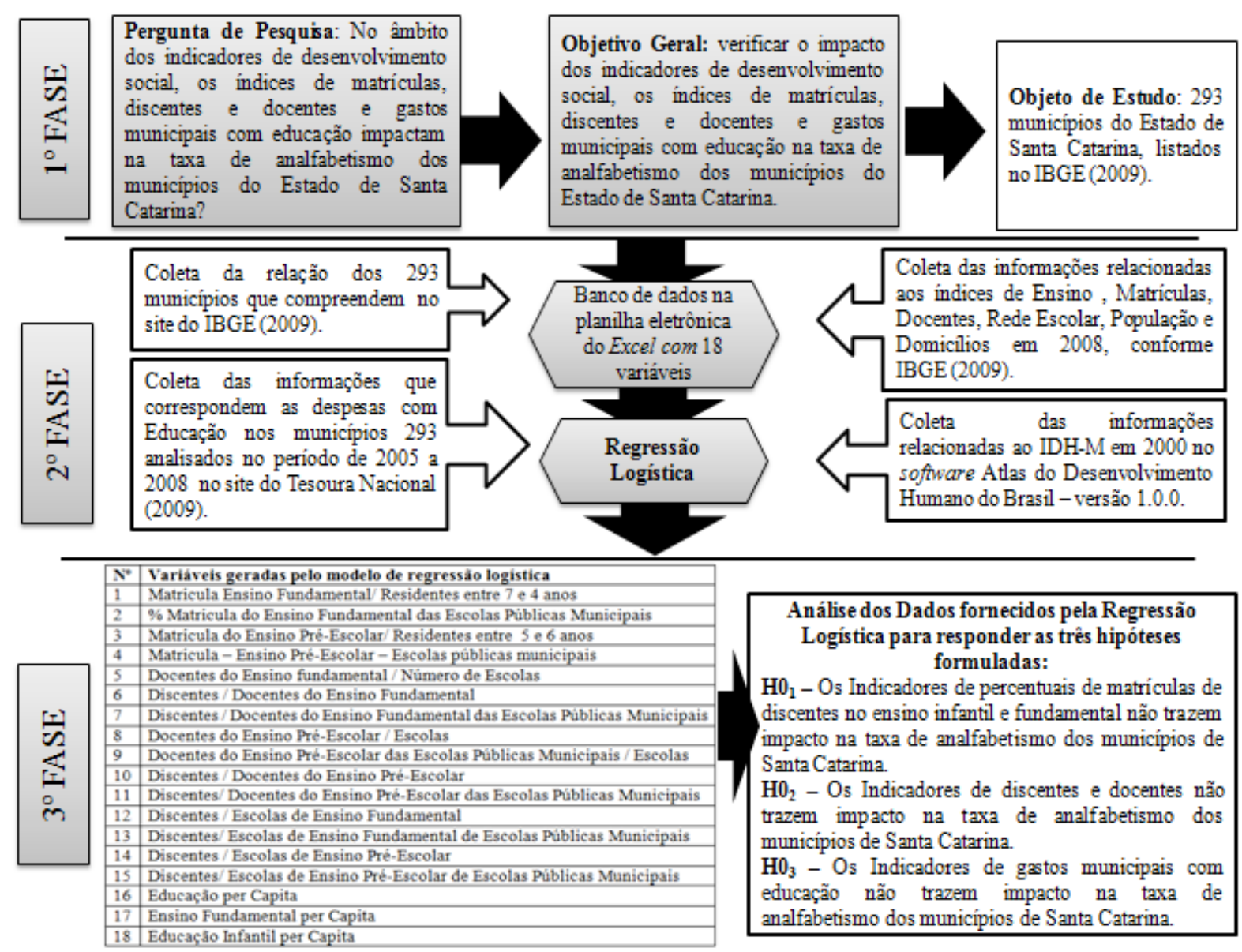

Figura 1. Design da pesquisa

Fonte: Elaborado pelos autores.

\section{ANÁLISE DOS RESULTADOS}

A seguir, são apresentados os resultados desta pesquisa, alcançados por meio do tratamento estatístico adotado na análise multivariada dos dados. Após a realização da análise de regressão logística pelo software aplicativo SPSS, o primeiro resultado exposto é um relatório demonstrativo de casos incluídos na análise, considerando-se as variáveis incluídas por meio da análise estatística, demonstradas na Tabela 2. 
Tabela 2. Demonstrativo de casos incluídos na análise

\begin{tabular}{|c|c|c|c|}
\hline \multicolumn{2}{|c|}{ Casos } & \multirow{2}{*}{$\begin{array}{c}\text { Número } \\
293\end{array}$} & \multirow{2}{*}{$\frac{\text { Percentual }}{100,0}$} \\
\hline & Incluídos nas análises & & \\
\hline Casos selecionados & Casos perdidos & 0 & 0,0 \\
\hline & Total & 293 & 100,0 \\
\hline Casos não selecionados & & 0 & 0,0 \\
\hline Total & & 293 & 100,0 \\
\hline
\end{tabular}

Fonte: Dados da pesquisa.

Na Tabela 2, observa-se que nenhum caso deixou de ser selecionado, atingindo um percentual de $100 \%$ da amostra aproveitada, uma vez que é composta por 293 observações e todas foram aproveitadas, ou seja, todos os 293 municípios do estado de Santa Catarina foram analisados. Na sequência, a Tabela 3 evidencia as variáveis inclusas na equação. Essas foram descritas anteriormente, na Figura 1.

Tabela 3. Variáveis inclusas na equação

\begin{tabular}{l|c|c|c|c|c|c|c}
\hline \multicolumn{2}{l|}{} & B & S.E. & Wald & DF & Sig. & e \\
\hline Step 0 (B) & Constante & 0,538 & 0,121 & 19,754 & 1 & 0,000 & 1,713 \\
\hline
\end{tabular}

Fonte: Dados da pesquisa.

Diante das informações apresentadas na Tabela 3, tem-se a estatística Wald. Esse primeiro resultado avalia a significância da constante inclusa no modelo. Segundo Corrar, Paulo, e Dias Filho, (2007, p. 305), "sua finalidade é verificar se é significativamente diferente de zero." Para tanto, a seguir, na Tabela 4 , evidenciam-se as variáveis não inclusas na equação. 
Tabela 4. Variáveis não inclusas na equação

\begin{tabular}{|c|c|c|c|c|}
\hline Proxies & Descrição & Escore & DF & Sig. \\
\hline MATRÍCULAS & $\begin{array}{l}\text { Matrícula Ensino Fundamental/Residentes entre } 7 \text { e } 14 \\
\text { anos }\end{array}$ & 5,674 & 1 & 0,017 \\
\hline V5 & $\begin{array}{l}\text { \% Matrícula - Ensino fundamental - Escola pública } \\
\text { municipal }\end{array}$ & 1,261 & 1 & 0,261 \\
\hline V6 & $\begin{array}{l}\text { Matrícula - Ensino pré-escolar/Residente entre } 5 \text { e } 6 \\
\text { anos }\end{array}$ & 12,6000 & 1 & 0,000 \\
\hline V7 & $\begin{array}{l}\text { Matrícula - Ensino pré-escolar - Escolas públicas mu- } \\
\text { nicipais }\end{array}$ & 7,751 & 1 & 0,005 \\
\hline DOCENTES & Docentes - Ensino fundamental/Escola & 33,015 & 1 & 0,000 \\
\hline V9 & Discentes/Docentes - Ensino fundamental & 4,185 & 1 & 0,041 \\
\hline V10 & $\begin{array}{l}\text { Discentes/Docentes - Ensino fundamental - Escola } \\
\text { pública municipal }\end{array}$ & 6,522 & 1 & 0,011 \\
\hline V11 & Docentes - Ensino pré-escolar/escola & 9,9988 & 1 & 0,002 \\
\hline V12 & $\begin{array}{l}\text { Docentes - Ensino pré-escolar - Escola pública } \\
\text { municipal/escola }\end{array}$ & 9,098 & 1 & 0,003 \\
\hline V13 & Discentes/Docentes - Ensino pré-escolar & 3,029 & 1 & 0,082 \\
\hline V14 & $\begin{array}{l}\text { Discentes/Docentes - Ensino pré-escolar - Escola pú- } \\
\text { blica municipal }\end{array}$ & 3,286 & 1 & 0,070 \\
\hline V15 & Discentes/Escolas - Ensino fundamental & 33,391 & 1 & 0,000 \\
\hline V16 & $\begin{array}{l}\text { Discentes/Escolas - Ensino fundamental - Escola pú- } \\
\text { blica municipal }\end{array}$ & 24,930 & 1 & 0,000 \\
\hline V17 & Discentes/Escolas - Ensino pré-escolar & 6,780 & 1 & 0,009 \\
\hline V18 & $\begin{array}{l}\text { Discentes/Escolas - Ensino pré-escolar - Escola públi- } \\
\text { ca municipal }\end{array}$ & 5,659 & 1 & 0,017 \\
\hline Per capita & Per capita - Educação & 14,142 & 1 & 0,000 \\
\hline V20 & Per capita - Ensino Fundamental & 29,581 & 1 & 0,000 \\
\hline V21 & Per capita - Ensino Infantil & 12,916 & 1 & 0,000 \\
\hline Estatísticas Globais & & 86,938 & 18 & 0,000 \\
\hline
\end{tabular}

Fonte: Dados da pesquisa.

A partir da análise da Tabela 4, tem-se a relação das proxies com os respectivos escores, em que se considera, em função do critério de classificação, que não seria consistente formular predições, sendo possível obter uma base comparativa que permita verificar se as proxies melhoram a qualidade das classificações. Sem incluí-las no modelo, o nível de acerto já alcançou $63 \%$. Dessa forma, com base na aplicação do modelo logístico e nos resultados obtidos e analisados, a Tabela 5 apresenta os testes Block e Model e os indicadores -2LL, Cox-Snell R2 e Nagelkerke R2, consolidados. 
Sabrina do Nascimento - Débora Gomes Machado - Jorge Eduardo Scarpin - Delci Grapégia Dal Vesco

Tabela 5. Testes e indicadores de validação do modelo de regressão logística

\begin{tabular}{l|c}
\hline \multicolumn{1}{c|}{ Testes e indicadores } & Resultados \\
\hline Block e Model & 101,541 \\
P-value & 0,000 \\
-2 LL & 284,168 \\
Nagelkerke R & 0,400 \\
Cox \& Snell R Square & 0,293 \\
\hline
\end{tabular}

Fonte: Dados da pesquisa.

Verifica-se na Tabela 5 que o valor foi de 101,541. Isso indica que é possível rejeitar a hipótese de que todos os parâmetros estimados são nulos, contribuindo para melhorar a qualidade das classificações. Para tanto, os indicadores -2LL (Log likelihood), Cox \& Snell e Nagelkerke também contribuem para avaliar o desempenho do modelo. No teste -2LL, de acordo com Hair et al. (2005, p. 264), a adequação da medida de ajuste compara as probabilidades previstas com as observadas, e os valores maiores indicam melhor ajuste. Analisando o valor no modelo de uma só variável, isto é, incluindo apenas a constante no modelo, tem-se o valor -2LL, que aumenta de 63 para 284,169. Destaca-se, ainda, que o teste Cox \& Snell se assemelha ao coeficiente de determinação R2 utilizado no modelo linear. Nesta pesquisa, ele indica que aproximadamente 29,3\% das variações ocorridas no log da razão de chance são explicadas pelo conjunto das proxies. O Nagelkerke fornece resultados entre 0 e 1 , indicando que o modelo é capaz de explicar $40 \%$ das variações registradas na variável classificatória. Cabe mencionar sobre os indicadores de regressão logística: -2LL, Cox-Snell R2 e Nagelkerke R2 (o primeiro avalia o ajustamento geral do modelo, e os resultados indicam que ele é adequado; os demais indicadores referem-se ao poder explicativo do modelo e apresentam resul- tados que evidenciam um poder explicativo satisfatório dos modelos). Essas interpretações embasam-se no exposto por Hair et al. (2005).

A seguir, com vistas a proporcionar um bom entendimento acerca das variáveis que pertencem ao Modelo de Regressão Logística, optou-se por dividi-las em três subitens: a) análise em relação às matrículas, b) análise em relação aos discentes e docentes, c) análise em relação aos gastos per capita e validação do modelo de regressão logística.

\section{Análise em relação às matrículas}

Em se tratando das quatro variáveis utilizadas como proxies dos indicadores de matrícula, o modelo rejeitou três delas: Matrículas Ensino Fundamental em relação aos Residentes entre 7 e 14 anos; Percentual de matrículas em relação ao Ensino Fundamental e à Escola pública municipal, e Matrícula em relação ao Ensino pré-escolar e à Escola pública municipal. Foram excluídas da equação de regressão logística por não indicarem interferência significativa com a variável classificatória dos Municípios com Analfabetismo $>10 \%$, visto que apresentaram grau de significância superior a 0,05 no teste Wald, conforme demonstrado na Tabela 6. 
Tabela 6. Variáveis excluídas da equação de regressão logística em relação às matrículas

\begin{tabular}{c|l|l|l|l}
\hline \multicolumn{1}{c|}{ Classificação } & \multicolumn{1}{|c|}{ Descrição } & Escore & DF & \multicolumn{1}{c}{ Sig. } \\
\hline Matrículas & $\begin{array}{l}\text { Matrícula Ensino Fundamental/Residentes entre 7 e } \\
14 \text { anos } \\
\% \text { Matrícula - Ensino Fundamental - Escola pública } \\
\text { municipal } \\
\text { Matrícula - Ensino pré-escolar - Escola pública muni- } \\
\text { cipal }\end{array}$ & 0,059 & 1 & 0,809 \\
\hline
\end{tabular}

Fonte: Dados da pesquisa.

A variável correspondente ao indicador de matrícula que permitiu verificar o impacto no indicador de analfabetismo foi o percentual de matrícula no ensino pré-escolar em relação ao total de residentes entre 5 e 6 anos no município, como evidenciado na Tabela 7.

Tabela 7. Variáveis da equação de regressão logística em relação às matrículas

\begin{tabular}{c|l|c|c|c|c|c|c}
\hline & & B & S.E. & Wald & DF & Sig. & e e $^{\operatorname{Exp}(\mathrm{B})}$ \\
\hline Variáveis do Modelo de Regressão Logística & $\begin{array}{l}\text { Matrícula - Ensino pré-escolar/Residentes } \\
\text { entre } 5 \text { e } 6 \text { anos }\end{array}$ & 1,719 & 0,700 & 6,030 & 1 & 0,014 & 5,581 \\
\hline
\end{tabular}

Fonte: Dados da pesquisa.

Tal constatação tem como base o coeficiente beta da proxy para o percentual de matrícula no ensino pré-escolar em relação ao total de residentes entre 5 e 6 anos no município o qual apresentou uma associação positiva de 1,719. Segundo Hair et al. (2005, p. 132), o beta permite uma "comparação direta entre coeficientes e seus poderes relativos de explicação da variável classificatória" neste estudo - o indicador de analfabetismo nos municípios de Santa Catarina. Para analisar a significância de cada coeficiente em particular, utilizou-se a estatística Wald, cujo objetivo é testar a hipótese nula de que determinado coeficiente não é significativamente diferente de zero.

Como se observa, o coeficiente de percen- tual de matrícula no ensino pré-escolar em relação ao total de residentes entre 5 e 6 anos é positivo, isso significa que uma variação positiva nesse índice contribui para aumentar a probabilidade de o município ter baixo índice de analfabetismo, uma vez que o valor preditivo da dummy apresentando o baixo índice de analfabetismo é um. Dessa forma, foi possível rejeitar HO1 para matrícula como nula. Assim, a pesquisa indicou que o percentual de discentes matriculados no ensino fundamental trouxe reflexos no indicador de analfabetismo municipal. Esse resultado se mostra positivo e demonstra progresso em relação à meta de redução do analfabetismo, contrário aos achados de Pinto et al. (2000), que demonstraram que a matrícula e a frequência da escola não eram 
suficientes para sua redução.

Análise em relação aos discentes e docentes

Verifica-se que das onze variáveis utilizadas como proxies dos indicadores discentes e docentes, o modelo rejeitou sete delas: docentes do ensino fundamental em relação à escola; discentes em relação aos docentes do ensino fundamental; discentes em relação aos docentes do ensino fundamental e às escolas públicas municipais; docentes do ensino pré-escolar em relação às escolas; docentes do ensino pré-escolar em relação às escolas públicas municipais e às escolas; discentes em relação aos docentes do ensino pré-escolar, e discentes em relação às escolas do ensino fundamental. Elas foram excluídas da equação de regressão logística por não indicarem interferência significativa com a variável classificatória dos Municípios com Analfabetismo > 10\%, sendo que se apresentou um grau de significância superior a 0,05 no teste Wald, de acordo com as informações dispostas na Tabela 8.

Tabela 8. Variáveis excluídas da equação de regressão logística em relação aos discentes e docentes

\begin{tabular}{c|l|l|l|l}
\hline Classificação & \multicolumn{1}{|c|}{ Descrição } & Escore & DF & Sig. \\
\hline Discentes e Docentes & Docentes - Ensino fundamental/escola & 0,017 & 1 & 0,895 \\
& Discentes/Docentes - Ensino fundamental & 0,013 & 1 & 0,909 \\
& Discentes/Docentes - Ensino fundamental - Escola pública muni- & 0,011 & 1 & 0,915 \\
& cipal & 0,414 & 1 & 0,520 \\
& Docentes - Ensino pré-escolar/Escola & 1,021 & 1 & 0,312 \\
& Docentes - Ensino pré-escolar/Escola pública municipal/Escola & 0,047 & 1 & 0,828 \\
& Discentes/Docentes - Ensino pré-escolar & 0,013 & 1 & 0,910 \\
\hline
\end{tabular}

Fonte: Dados da pesquisa.

Com base nos dados apresentados na Tabela 9 , percebe-se que as variáveis correspondentes ao indicador discentes e docentes, que permitiram verificar o impacto no indicador analfabetismo, foram as seguintes variáveis: discentes em relação aos docentes de ensino pré-escolar e às escolas pú- blicas municipais; discentes em relação às escolas de ensino fundamental e às escolas públicas municipais; discentes em relação às escolas de ensino pré-escolar, e discentes em relação às escolas de ensino pré-escolar e às escolas públicas municipais, de acordo com a Tabela 9. 
Tabela 9. Variáveis da equação de regressão logística em relação aos discentes e docentes

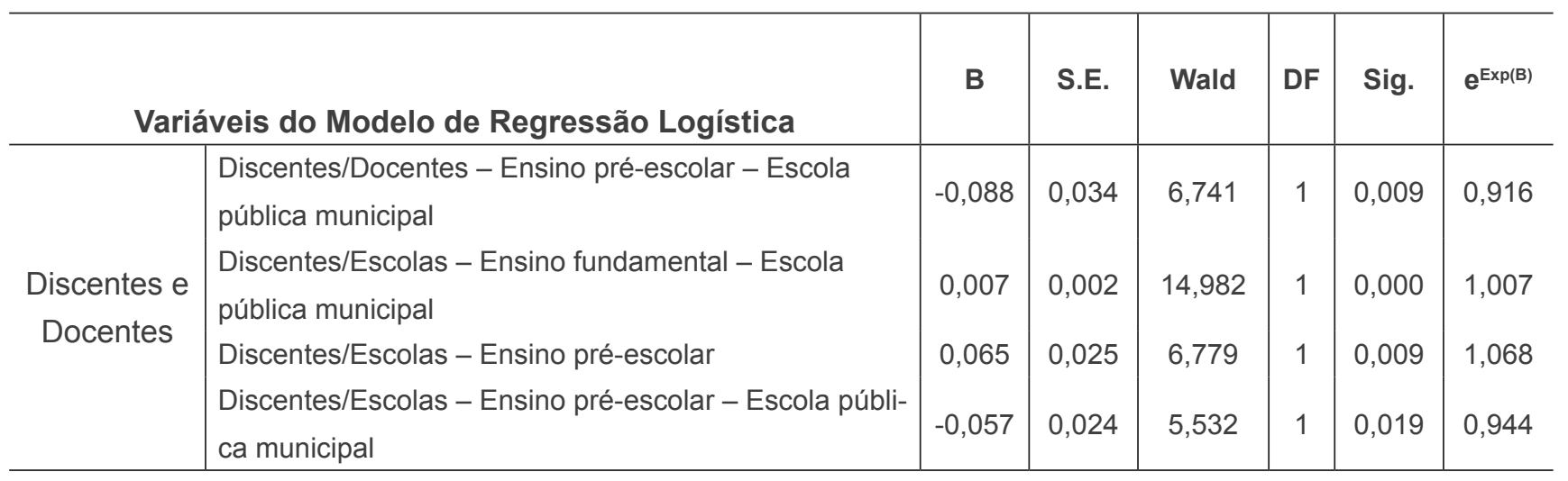

Fonte: Dados da pesquisa.

Destaca-se que as variáveis evidenciadas na Tabela 9 compõem o modelo de regressão logística devido aos valores que apresentam no coeficiente beta da Proxy para os Discentes em relação aos docentes de ensino pré-escolar e às escolas públicas municipais, o qual apresentou uma associação negativa de 0,088, na variável Discentes em relação às escolas de ensino fundamental e às escolas públicas municipais, cuja variável apresentou uma associação positiva de 0,007. Na variável Discentes em relação às escolas de ensino pré-escolar, a associação se deu de forma positiva $(0,065)$ e a variável Discentes em relação às escolas de ensino pré-escolar e às escolas públicas municipais obteve uma negativa de 0,057. Assim, infere-se que essas variáveis contribuíram para aumentar a probabilidade de o município ter um baixo índice de analfabetismo, apresentando valor preditivo dummy e baixo índice de analfabetismo igual a um. Dessa maneira, foi possível rejeitar a $\mathrm{HO} 2$ para discentes e docentes como nula, demonstrando que o percentual de discentes e docentes tem impacto sobre o indicador de analfabetismo dos municípios investigados.

Análise em relação aos gastos municipais com educação

Em relação a três variáveis utilizadas como proxies dos indicadores gastos per capita, observa-se que o modelo rejeitou a variável Per capita educação, a qual foi excluída da equação de regressão logística por não indicar interferência significativa com a variável classificatória dos Municípios com Analfabetismo $>10 \%$, sendo que apresentou um grau de significância superior a 0,05 no teste Wald, apresentado na Tabela 10.

Tabela 10. Variáveis excluídas da equação de regressão logística em relação aos gastos municipais com educação

\begin{tabular}{c|l|l|l|l}
\hline \multicolumn{1}{c|}{ Classificação } & \multicolumn{1}{|c|}{ Descrição } & Escore & DF & Sig. \\
\hline Contábil & Per capita - Educação & 0,124 & 1 & 0,725 \\
\hline
\end{tabular}

Fonte: Dados da pesquisa. 
De acordo com as informações da Tabela 10 , verifica-se que as variáveis correspondentes ao indicador gastos per capita, que permitiram verificar o impacto no indicador analfabetismo, foram as variáveis Ensino fundamental per capita e Educação infantil per capita, evidenciadas na Tabela 11.

Tabela 11. Variáveis da equação de regressão em relação aos gastos municipais com educação

\begin{tabular}{l|l|c|c|c|c|c|c}
\hline & & & & & & \\
\multicolumn{2}{c|}{ Variáveis do Modelo de Regressão Logística } & & S.E. & Wald & DF & Sig. & $\mathbf{e}^{\operatorname{Exp(B)}}$ \\
\hline \multirow{2}{*}{ Contábeis } & Per capita - Ensino Fundamental & $-0,007$ & 0,001 & 27,395 & 1 & 0,000 & 0,993 \\
& Per capita - Educação Infantil & 0,017 & 0,005 & 11,561 & 1 & 0,001 & 1,017 \\
\hline
\end{tabular}

Fonte: Dados da pesquisa.

Verifica-se que as variáveis Ensino fundamental per capita e Educação infantil per capita, apresentadas na Tabela 10, compõem o modelo de regressão logística, devido aos valores que apresentam no coeficiente beta da Proxy para a Ensino fundamental per capita - com associação negativa de 0,007 -e para a Educação infantil per capita - com associação positiva de 0,017.

Nesse contexto, verifica-se que essas variáveis contribuíram para aumentar a probabilidade de o município ter um baixo índice de analfabetismo, pois apresenta valor preditivo dummy, que representa o baixo índice de analfabetismo como sendo igual a um. Dessa maneira, foi possível rejeitar a $\mathrm{HO} 3$ para os gastos per capita como nula, evidenciando a relevância dessas variáveis no impacto sobre o indicador de analfabetismo.

O estudo de Campos e Cruz (2009) destaca que é possível argumentar que a disponibili- dade de recursos é condição necessária, porém não suficiente, para se consolidar uma educação pública de qualidade. Bom senso, vontade política e discernimento por parte dos governantes também são metas desejáveis e essenciais. Dessa forma, a relação dos gastos e da taxa de analfabetismo pode sofrer influência da existência de recursos, mas, conforme sugerem os autores, é necessário assegurar que esses recursos sejam bem aplicados. Fernandes et al. (2008) ressaltam que o bom gerenciamento das políticas públicas, aliado à maior disponibilidade orçamentária, é fator decisivo para a educação de qualidade.

Validação do modelo de regressão log ística

A seguir, a Tabela 12 apresenta a validação do modelo de regressão logística, que tem como propósito validar as três hipóteses preestabelecidas. 
Tabela 12. Validação do modelo de regressão logística

\begin{tabular}{c|l|c|c|c}
\hline \multicolumn{2}{c|}{ Validação do modelo de regressão logística } & $\begin{array}{c}\text { Municípios com } \\
\text { Analfabetismo } \\
<10 \%\end{array}$ & $\begin{array}{c}\text { Municípios com } \\
\text { Analfabetismo } \\
>10 \%\end{array}$ & $\begin{array}{c}\text { Percentual } \\
\text { Correto }\end{array}$ \\
\hline $\begin{array}{c}\text { Variáveis classifica- } \\
\text { tórias }\end{array}$ & $\begin{array}{l}\text { Municípios com Analfabetismo < } \\
10 \% \\
\text { Municípios com Analfabetismo > } \\
10 \%\end{array}$ & 64 & 44 & 59,3 \\
\hline Percentual total & 29 & 156 & 84,3 \\
\hline
\end{tabular}

**Ponto de corte igual a 0,500 .

Fonte: Dados da pesquisa.

Pela análise da Tabela 12, observa-se que o percentual de acerto do modelo é de $75,1 \%$, superando a previsão inicial de $63 \%$.

\section{CONSIDERAÇÕES FINAIS}

Por meio da pesquisa descritiva e correlacional com abordagem quantitativa, utilizando como método a análise multivariada dos dados com a técnica de Regressão Logística, este estudo avaliou o impacto dos indicadores de desenvolvimento social - índices de matrículas, de discentes e docentes e dos gastos municipais com educação - na taxa de analfabetismo dos municípios do estado de Santa Catarina. Foram analisados 293 municípios, por meio de três hipóteses.

Em relação à primeira hipótese de pesquisa, os Indicadores de percentuais de matrícula de discentes no ensino fundamental não trazem impacto na taxa de analfabetismo dos municípios de Santa Catarina, pois apresentaram uma rejeição parcial. Das quatro variáveis testadas, três delas (número de matrícula no Ensino Fundamental dividido pela população residente entre $7 \mathrm{e}$ 14 anos, percentual de matrícula no ensino fundamental em escola pública municipal e percentual de matrícula no ensino pré-escolar em escola pública municipal) foram rejeitadas. Por sua vez, o número de matrícula no ensino pré-escolar, dividido pela população residente entre 5 e 6 anos, mostrou-se significante, apresentando bom relacionamento positivo e baixo indicador de analfabetismo, o que mostra que há forte indício de que o analfabetismo se dá pela não saída das crianças da escola do ensino pré-escolar para o ensino fundamental.

Já na segunda hipótese de pesquisa, os Indicadores percentuais de discentes e docentes não causam impacto na taxa de analfabetismo dos municípios de Santa Catarina (variáveis parcialmente rejeitadas), pois a relação entre o número de professores quanto ao número de escolas, entre o número de professores em relação ao número de alunos e entre o número de alunos quanto ao número de escolas teve como rejeição apenas as seguintes variáveis: número de alunos em relação ao número de professores no Ensino pré-escolar na Escola pública municipal, número de alunos quanto ao número de professores no Ensino fundamental na Escola pública municipal e número de discente por 
escola no ensino pré-escolar como um todo e no ensino pré-escolar em escola pública municipal. Nessas variáveis, ficou evidenciado que, principalmente no ensino pré-escolar, um número alto de alunos por professor prejudica a taxa de analfabetismo. Tais variáveis mostraram indicadores negativos, comprovando que turmas pequenas podem produzir melhores resultados.

Finalmente, na terceira hipótese de pesquisa, os Indicadores de gastos municipais com educação não provocam impacto à taxa de analfabetismo dos municípios de Santa Catarina (variáveis também parcialmente rejeitadas), principalmente porque um maior gasto no ensino infantil (equivalente ao pré-escolar) pode produzir melhores indicadores de analfabetismos. Sendo assim, os resultados da pesquisa apontam para uma confirmação da teoria quando demonstram que os gastos públicos e a forma de gerenciamento impactam nos indicadores de qualidade do ensino, assim como defendido por Fernandes et al. (2008) e Campos e Cruz (2009). Entretanto, isso se mostrou mais eficaz no ensino pré-escolar, o que pode evidenciar que, quanto mais cedo a criança entra na escola e quanto mais o município investe nessas crianças (de 5 a 6 anos), meIhor o aproveitamento nos indicadores totais de analfabetismo da população. Nesse contexto, sugere-se para futuras pesquisas a replicação deste estudo em futuras gestões de governo do estado de Santa Catarina, observando se continuam apresentando os mesmos resultados, além de estudar o tema expandido para as outras unidades da $\mathrm{Fe}$ deração.

\section{REFERÊNCIAS}

Boudon, R. (1989). Os métodos em sociologia. São Paulo: Ática.

Campos, B. C., \& Cruz, B. P. A. (2009). Impactos do Fundeb sobre a qualidade do ensino básico público: Uma análise para os municípios do estado do Rio de Janeiro. Revista de Administração Pública, 43(2), 371-393.

Cooper, D. R., \& Schindler, P. S. (2003). Métodos de pesquisa em administração. 7a ed. São Paulo, SP: Bookman.

Corrar, L. J., Paulo, E., \& Dias Filho, J. M. (2007). Análise multivariada de dados para Cursos de Administração, Ciências Contábeis e Economia. São Paulo, SP: Atlas.

Dal Vesco, D. G. (2008). Impactos da alteração da gestão do governo estadual nos Indicadores contábeis das concessionárias de rodovias do estado do Paraná de 1996 a 2006: Um estudo empírico. Dissertação de mestrado, Universidade Federal do Paraná, Curitiba, PR, Brasil.

Fernandes, C. C. P., Silveira, S. F. R., Vieira, L. H. S., \& Quirino, S. G. (2008). Representações sociais de políticas educacionais no universo da gestão pública municipal: Um estudo de multicasos. Encontro de Administração Pública e Governança, Salvador, BA, Brasil, 3.

Ferranti, D., Perry, G. E., Gill, I., Guasch, J. L., Maloney, W. F., Sanchez-Paramo, C., \& Schady, N. (2002). Closing the gap in education and technology. Washington, DC: The World Bank, Latin America and Caribbean Department.

Flug, K., Spilimbergo, A., \& Wachtenheim, E. 
(1996). Investment in education: Do economic volatility and credit constraints matter? BID, Working Paper Series, 301.

Hair Jr., J. F., Anderson, R. E., Tatham R. L., \& Black W. C. (2005). Análise Multivariada de Dados. Porto Alegre, RS: Bookman.

Instituto Brasileiro de Geografia e Estatística. (2016). Censo Demográfico 2000: Características da população e dos domicílios: resultados do universo. Recuperado de www.ibge.gov.br/home/estatistica/populacao/censo2000

Instituto Nacional de Estudos e Pesquisas Educacionais Anísio Teixeira - Ministério da Educação e Cultura - MEC. (2001). Geografia da Educação Brasileira. Brasília. CD-ROM.

Lorenzo, C. (2007). O consentimento livre e esclarecido e a realidade do analfabetismo funcional no Brasil: Uma abordagem para a norma e para além da norma. Revista Bioética, 15(2), 268-282.

Lüdke, M., \& André, M. E. D. A. (1986). Pesquisa em educação: Abordagens qualitativas. São Paulo, SP: EPU.

Marconi, M. A., \& Lakatos, E. V. (1999). Técnica de pesquisa. 4a ed. São Paulo: Atlas.

Maroco, J. (2007). Análise Estatística com utilização do SPSS. 3a ed. Lisboa: Edições Sílabo.

Marquetti, D. A., Berni, D. A., \& Hickmann, A. M. (2005). Determinantes dos diferenciais das taxas de crescimento sub-regionais do Rio Grande do Sul nos anos 90. Ensaios
FEE, 26(esp.), 95-116.

Oliveira, S. L. (2001). Tratamento de metodologia científica. São Paulo: Pioneira Thomson Learning.

Paiva, V. (1998). Educação e mundo do trabalho: Notas sobre formas alternativas de inserção de setores qualificados. Revista Contemporaneidade e Educação, 3(4), 8-21.

Pereira, D. R. M. (2009). Não apenas pergunte à educação o que ela pode fazer pelo desenvolvimento humano, mas também ao desenvolvimento humano o que ele pode fazer pela qualidade da educação. Encontro da Associação Nacional dos Programas de Pós-Graduação em Administração, São Paulo, SP, Brasil, 33.

Pimentel, E. A., \& Haddad, E. A. (2005). Convergência do capital humano: $A$ dimensão educacional da desigualdade regional no Brasil, 1991-2000. Encontro CAEN/UFC-EPGE/FGV de Políticas Públicas e Crescimento Econômico, Fortaleza, CE, Brasil, 2.

Pinto, J. M. R, Brant, L. L. N. A. O., Sampaio, C. E. M., \& Pascom, A. R. P. (2000). Um olhar sobre os indicadores de analfabetismo no Brasil. R. Bras. Est. Pedag., 81(199), 511-524.

Psacharopoulos, G. (1994). Returns to investiment in education: A global update. World Development, 22(9), 1325-1343.

Sampieri, R. H., Collado, C. F., \& Lucio, P. B. (2006). Metodologia e pesquisa. 3a ed. São Paulo, SP: McGraw-Hill.

Scarpin, J. E. (2006). Estudo dos fatores condicionantes do Índice de desenvolvimento 
humano nos municípios do estado do Paraná: Instrumento de controladoria para a tomada de decisões na gestão governamental. Tese de Doutorado, Universidade de São Paulo, São Paulo, SP, Brasil.

Slomski, V. (2001). Manual de contabilidade pública: Um enfoque na contabilidade municipal, de acordo com a Lei de Responsabilidade Fiscal. São Paulo, SP: Atlas.

Slomski, V., Rezende, A. J., Athayde, T. R., \& Carvalho, E. M. (2004). A controladoria e a gestão pública dos programas sociais: Um estudo dos impactos dos programas sociais na renda econômica e financeira de famílias carentes no município Três Lagoas - MS. Encontro da Associação Nacional dos Programas de Pós-graduação em Administração, Curitiba, PR, Brasil, 28.
Tesouro Nacional. Recuperado de www.tesouro.fazenda.gov.br

Varela, P. S., \& Martins, G. A. (2005). Indicadores sociais no processo orçamentário do setor público: Possibilidades e limites. Encontro da Associação Nacional dos Programas de Pós-Graduação em Administração, Brasília, DF, Brasil, 24.

Varela, P. S., Martins, G. A. M., \& Corrar, L. J. (2006). Perfil dos gastos públicos versus perfil econômico-social dos municípios paulistas. Encontro de Administração Pública e Governança, Salvador, BA, Brasil, 2.

Vieira, M. A. L. (2006). Educação de adultos, analfabetismo e pobreza em Moçambique. Tese de Doutorado, Universidade Metodista de Piracicaba - Unimep, Piracicaba, São Paulo, SP, Brasil. 